\title{
Belphégor
}

\section{Notes sur « Le retournement parodique des discours à leurres constants »}

\section{Alain Vaillant}

\section{(2) OpenEdition}

1 Journals

\section{Electronic version}

URL: https://journals.openedition.org/belphegor/1276

DOI: $10.4000 /$ belphegor.1276

ISSN: 1499-7185

Publisher

LPCM

\section{Electronic reference}

Alain Vaillant, "Notes sur « Le retournement parodique des discours à leurres constants »", Belphégor [Online], 16-1 | 2018, Online since 04 July 2018, connection on 19 October 2021. URL: http:// journals.openedition.org/belphegor/1276 ; DOI: https://doi.org/10.4000/belphegor.1276

This text was automatically generated on 19 October 2021

\section{(c)}

Belphégor est mis à disposition selon les termes de la Licence Creative Commons Attribution - Pas d'Utilisation Commerciale - Pas de Modification 4.0 International. 


\title{
Notes sur « Le retournement parodique des discours à leurres constants »
}

\author{
Alain Vaillant
}

1 Prononcée dans le cadre du colloque de Cerisy « Dire la parodie », cette contribution au titre aussi mystérieux que séduisant (je ne suis d'ailleurs pas très sûr de l'avoir vraiment compris) communique à son lecteur la sensation de vertige habituelle à ceux qui étaient familiers aux prises de parole ou aux publications de Charles Grivel : vertige devant une fausse logorrhée où l'on croyait, à chaque instant, que le théoricien prodigieusement virtuel allait se perdre, pour le plaisir d'une formule, dans une envolée redondante ou une digression hors de propos mais qui, toujours, aboutissait à une proposition lumineuse, faussement incidente, touchant en fait à l'essentiel et ouvrant sur des perspectives décisives. Mais ici, il s'agit d'un vertige au carré, puisqu'on devine que Grivel, en commençant par décréter que toute écriture est auto-parodique, se propose malicieusement d'appliquer son écriture vertigineuse à réfléchir (à) son propre vertige pour mieux le comprendre. Il se fait humoriste : Il note au passage, dans l'une des innombrables pépites théoriques qu'il sème en chemin, que la parodie, au contraire de l'ironie satirique qui conforte confortablement le scripteur, est du côté de l'humour. Car, malgré les apparences, la vraie cible du parodiste est lui-même, la parodie est toujours «construite en trompe-l'œil». Si bien que le brillant exercice d'équilibrisme conceptuel sur la parodie auquel Grivel se prête avec une jubilation très palpable aboutit à un texte très personnel où, sans doute, son auteur se livre beaucoup plus qu'on ne s'y attendait.

Dans le détail, il est toujours très difficile de résumer un texte de Grivel : toujours trop elliptique, trop dense, trop erratique - à tous égards, très éloigné des normes actuelles $\mathrm{du}$ discours universitaire. On peut craindre, d'ailleurs, que la difficulté réelle qu'éprouve le lecteur à tirer des leçons claires, univoques et aisément applicables de sa pensée constitue le principal danger pour sa postérité. Je ne m'essaierai donc pas à un tel exercice de synthèse - d'autant que, en 1985, la parodie est loin d'être un sujet neuf, 
et qu'il faudrait commencer par faire le tri entre les échos déformés du débat collectif et les thèses personnelles. Outre Palimpsestes, de Genette (l'approche poéticienne ne fait pas partie de l'horizon théorique de Grivel et l'essai n'est même pas cité en bibliographie), évoquons seulement le collectif Le Singe à la porte, que, en 1984, le collectif Groupar venait de publier chez Peter Lang et qui, lui, est à plusieurs reprises cité.

3 Donc, on sait bien que le domaine de la parodie est sans limites, que tout texte est la parodie d'une infinité d'autres, que la parodie n'est pas un discours secondaire ni même second. On le sait et Grivel le dit aussi, mais sans s'y arrêter. Car la vraie question est de savoir quel est l'intérêt de ce déluge d'imitations parodiques. À se moquer, à ironiser, à se distancier, soit. Mais à quoi bon ? Une fois suffirait, ou seulement de temps à autre, comme une simple hygiène de l'esprit. Or Grivel, dès les premières lignes, propose un renversement capital : non plus d'examiner la relation avec le parodié et le parodiant (cela ne peut donner, en effet, que de laborieuses classifications genettiennes), mais «de renverser le point de vue » et « d'explorer le nœud que fait le parodique avec sa vérité ». Car le véritable enjeu de la parodie est le face-à-face du sujet avec lui-même, la ruse qu'il doit employer pour se regarder lui-même (sans vraiment oser se regarder: l'inconscient et la psychanalyse ne sont pas loin). Or, si « je est un autre ", et même beaucoup d'autres, le «je » doit faire accueil à ces altérités et en assumer le risque : " soyons divers, soyons tout ce que nous sommes ", nous exhorte Grivel.

4 C'est pourquoi la parodie donne accès à des vérités infiniment plus sérieuses et plus graves que ne l'imagine l'idéologie postmoderniste. Au passage, Grivel en profite pour suggérer lui aussi une classification, qui cache mal une hiérarchie de ses dilections. Il y aurait donc le premier degré de la parodie, le "parodique d'excès", les effets hyperboliques des romans populaires, qui se caricaturent à force d'exagérations volontaires et ostensibles. Ce n'est pas très fin, mais c'est une preuve de bonne santé littéraire : on sent que Grivel a de l'affection pour ces jeux innocents dont le plaisir est communicatif. Puis il y aurait le "parodique de généralisation", où un texte systématise sérieusement les procédés d'un autre. C'est le parodique triste, que Grivel repère dans les répliques ou les sous-produits du Nouveau Roman. Et, puisque la parodie est dans le texte comme le ver dans le fruit, il est inutile de préciser que le Nouveau Roman lui-même ne sort pas indemne de l'opération. Enfin, arrive la parodie "de degré tiers ", la "relance parodique indéfinie ", qui est la parodie à son meilleur : Grivel la trouve chez Renaud Camus, Jean-Claude Pirotte et Denis Roche. Du moins le dit-il : il n'est pas assez immodeste pour écrire franchement qu'il est le véritable artiste de la « relance parodique indéfinie » (car la parodie est un art, écrit-il encore).

5 À trente ans de distance, ses appréciations à l'emporte-pièce sur ses contemporains n'ont donc guère d'importance. Beaucoup moins que la formule allégorique qui clôt l'article. Le parodiste, conclut Grivel, est un «faux caméléon». C'est-à-dire un vrai caméléon. Car le caméléon est faux par nature : plus il s'évertue à se faire passer pour des autres que lui-même, plus il persévère dans son être et se réalise pleinement, si bien que c'est en se cachant, en se projetant dans l'apparence de l'autre, « qu'il devient lui-même ». Or tout écrivain, tout scripteur conscient de lui-même, est ce faux caméléon, puisqu'il sait bien, mieux que tout autre, qu'il est toujours condamné à employer le langage des autres, "les mots de la tribu ». Puis Grivel ajoute ces derniers mots: "Ainsi du parodieur, à la langue longue, mobile, rapide et courbe». Fin de l'autoportrait. 
INDEX

Mots-clés: Grivel, rire, parodie 